Editorial

\title{
The biomedical community and the biological and toxin weapons convention
}

\author{
Simon Whitby ${ }^{1}$ and Malcolm Dando ${ }^{2}$
}

Published: 15 August 200I

BMC News and Views 200I, 2:6

Negotiations to find a legally binding way to strengthen the Biological and Toxin Weapons Convention (BTWC) of 1972 [1] are in danger of failing. The crisis was precipitated during the current round of talks, now in its final week in Geneva, when the US, alone amongst the negotiating States, rejected the text of a protocol that has taken six and a half years to negotiate.

The US argues that the measures in the text would not prevent the proliferation of biological weapons and that the measures intended to enable verification of compliance with the Convention would not be successful. Although the US remains committed to looking for new ways to prevent proliferation and to enable verification, failure to find agreement now could, given that arms negotiations traditionally extend over many years, lead to a hiatus of five or more years at a dangerous time when biomedicine is reaping the knowledge of the genomic revolution. Such a failure would send out the wrong message to those countries that intelligence reports suggest are conducting programmes to develop biological weapons.

The biomedical community obviously is focussed on the health benefits of the new biomedicine, but is must play a bigger role also in preventing the malign misuse of this dual-use technology, because genomics opens up the possibility of creating militarily significant weapons. That is, advances in biomedicine mean that there is a real possibility of designing weapons that are stable, reliable, predictable, discriminating, fast acting, dispersible and do not backfire on the user, and so have real potential as tactical and strategic weapons.

Potential novel biological weapons include:
Benign microorganisms, genetically modified to produce a toxin, venom sub fraction or endogenous bioregulator;

Microorganisms resistant to antibiotics, standard vaccines and therapeutics;

Microorganisms with enhanced aerosol and environmental stability;

Immunologically altered micro organisms able to defeat standard identification, detection and diagnostic methods; and

Combinations of the above coupled with improved delivery systems.

To prevent proliferation of such weapons, the international community pursues a range of policies. These are referred to as a "web of deterrence" and they include:

- An international prohibition regime;

- Broad controls on the use and transfer of dangerous pathogens;

- Detection, protection and treatment measures; and

- Determined international responses to any use or threat of use of biological weapons.

Of these the international prohibition regime is the lynchpin. It is based first on the 1925 Geneva Protocol which bans the use of chemical and biological weapons. 
The 1975 Biological and Toxin Weapons Convention (BTWC) supplements the 1925 Protocol. Its scope is set out in Article I which states that:

"Each State Party to this Convention undertakes never in any circumstances to develop, produce, stockpile or otherwise acquire or retain:

1.Microbial or other biological agents, or toxins whatever their origin or method or production, of types and in quantities that have no justification for prophylactic, protective or other peaceful purposes..."

Thus there is nothing wrong with the sweeping scope of the Convention. The problem is that the BTWC was negotiated during the Cold War and no agreement could be reached then on a mechanism to verify that the States Parties were living up to their obligations.

Efforts were made in the 1980 s to strengthen the BTWC through voluntary annual data exchanges (Confidence Building Measures) but these failed. So after the fears that Iraq might have used biological weapons in the 1991 Gulf War more serious efforts began to find a legally binding verification mechanism. These efforts started with a two-year scientific and technical investigation of potential verification mechanisms in the process that is known as VEREX.

Amongst the wide range of measures assessed were certain elements such as sampling and identification on-site and medical examination where biomedical science could play a part. However, as the process of negotiation amongst the 140 plus states got underway in earnest in the later 1990s the role seen for such measures was much reduced in relation to compliance as they were judged to be too intrusive to be widely acceptable.

The compliance measures in the Protocol to the BTWC now under negotiation are based on three strands:

-Declarations by each State Party of the most relevant facilities;

-Visits to check the validity of the declarations; and

-Challenge inspection of both facilities and field when there are well-founded suspicions of violations.

It is really only in relation to challenge inspections which are likely to be rare - that sampling may be used.
The inspections would be carried out by a professional team trained by a yet to be established BTWC Organisation. These people would have a biomedical or engineering background and be subject to high levels of confidentiality, thus ensuring that legitimate commercial confidentiality and national security information would be protected.

\section{The indirect effect of cooperation}

However, the BTWC also has a second aspect of the encouragement of cooperation in relevant technologies, and here the potential role of biomedical sciences in strengthening the Convention is much stronger. Whilst advanced industrialised countries see the prohibition regime as an overall enhancement to international security because of its total prohibition against biological weapons, developing countries have tended to see the regime in terms of improvements in the flow of scientific and technological exchange between north and south. It is envisaged in the Protocol text that the biomedical science community would engage in cooperative activities in the following areas:

\section{Sharing information on the peaceful use of biomedicine} Therefore, a future BTWC organisation might facilitate greater cooperation between north and south in regard to the collection and dissemination of information on the peaceful used of biomedical technologies including biotechnology. For example, greater cooperation in this area will lead to further strengthening the existing international initiatives such as the Biosafety Clearing House Mechanism as established under Article 18 of the Convention on Biodiversity.

\section{Technology transfer}

Further benefits will flow from greater cooperation between north and south on scientific, technical, environmental and legal information on experience with the environmental release of genetically modified organisms. Greater transparency in these areas will bring benefits to all countries involved.

\section{Good manufacturing and laboratory practice}

Risks to the BTWC will reduce as standards relating to Good Manufacturing, and Good Laboratory practice in pharmaceutical and medicinal production rise around the world as a result of the harmonisation of international guidelines. The promotion of measures to assist all countries to adopt national standards for GLP and GMP would bring scientific, technological and economic benefits to countries through enhanced trade whilst at the same time contributing to increased confidence in compliance with the regime that prohibits biological weapons. 


\section{Harmonisation}

Further to this, the harmonisation worldwide of standards relating to biological containment would result in increased confidence that biological microorganisms are being handled, stored, and used safely and for permitted purposes. In addition to the provisions set out under the BTWC, improved worldwide cooperation of safety in biotechnology are being addressed in other international fora. For example, signatories to the Convention on Biodiversity [2] have adopted the Cartagena Biosafety Protocol and the Technical Guidelines on Safety in Biotechnology (relating to the safe handling, transfer and use of living modified organisms resulting from biotechnology) drawn up by the United Nations Environmental Programme (UNEP)[3]. Implementation of such guidelines has obvious implications for biomedical communities, and greater cooperation in these and other areas related to safety in biotechnology will increase confidence that signatories to the BTWC are in compliance with its terms.

\section{Databases}

Scientific and technical cooperation including cooperation in biotechnology would be further enhanced under a strengthened BTWC through the facilitation of access to databases containing information on the peaceful uses of biological agents and toxins, biosafety, and the results of scientific research in the life sciences.

\section{Emerging diseases}

Indeed, improvements in the collection and dissemination of information on the diagnosis, surveillance, detection, treatment and prevention of diseases caused by biological agents or toxins, particularly infectious diseases as envisaged under a strengthened BTWC prohibition regime would have far reaching implications for biomedical communities. Steps are already being taken by the $\mathrm{WHO}[4]$, the Office International des Epizooties (OIE)[5] and the Food and Agriculture Organization of the United Nations (FAO)[6] to develop strategies to strengthen the infrastructure for disease surveillance and to encourage research to develop new and effective disease surveillance and controls of relevance to diseases affecting humans, animals and plants. The implementation of improved measures in the above fields are of direct relevance to the BTWC.

\section{Handling and transport of biological agents}

Furthermore, steps to harmonise national, regional and international controls and regulations relating to the handling, transportation, use and release of biological agents and toxins will increase confidence that States are in compliance with the BTWC.

\section{The need for the BTWC}

In the last decades of the 2oth Century, the former Soviet Union, Iraq and South Africa had offensive biological warfare programmes. In the 1990s the US Congress Office of Technology Assessment stated that seven other countries were generally reported as having undeclared offensive biological weapons programmes. Closing down such programmes, and preventing their further proliferation, is an important goal for the international community as has frequently been made clear in high-level official statements.

\section{Conclusions}

A protocol strengthening compliance with the 1972 BTWC signed by those countries, particularly those such as the US that are leading opponents to the development of biological weapons and leaders in biomedicine, will do much to create an international environment hostile to the proliferation of biological weapons.

The Protocol's specific provisions, coupled with those of other elements of "the web of deterrence" aim to:

Make it more difficult for "proliferation governments" and sub-national groups to gain access to the materials needed for biological weapons programmes;

To build confidence among nations that signatories are complying with the terms of the BTWC; and

To make joining the BTWC a viable and attractive option for emerging economies.

The biomedical community has a role to play in furthering these aims. Yet, one of the major problems during the past decade when exploring ways to strengthen the BTWC has been the lack of interest and understanding amongst specialist and general publics of the growing dangers of biological warfare and the need for greater efforts to prevent such a dreadful deliberate use of disease as a weapon of war and terror.

Perhaps the greatest contribution that biomedical science can make to verification of the BTWC is to take an informed interest in the efforts of the international community and to use their undoubted standing and prestige to support the drive for an effective conclusion of a verification Protocol.

Simon Whitby Research Fellow, Department of Peace Studies, University of Bradford, UK.

Malcom Dando Professor of International Security, Department of Peace Studies, Universtity of Bradford, UK. 


\section{References}

I. The Biological and Toxin Weapons Convention. [http://projects.sipri.se/cbw/docs/bw-btwc-mainpage.html]

2. The convention on biodiversity. [http://www.gtz.de/biodiv/english/e_index.htm]

3. United Nations Environmental Programme. [http://www.unep.org/]

4. The World Health Organization. [http://www.who.int/home-page/]

5. Office International des Epizooties. [http://www.oie.int/]

6. The Food and Agriculture Organization. [http://www.fao.org/]

\section{(C) 2001 BioMedCentral Ltd}

